\title{
Memoria, resistencia y poder pacifico transformador de pueblos indígenas de Ias Amazonías colombiana y peruana*
}

\author{
Memory, resistance and the non-violent \\ transforming power of the indigenous peoples \\ in the Colombian and Peruvian Amazon
}

Esperanza Hernández Delgado**

Recibido: $14 / 01 / 2014$

Aprobado: 30/03/2014

Disponible en línea: 01/07/2014

\section{Resumen}

Este artículo recoge hallazgos preliminares de la investigación realizada por la Fundación Caminos de Identidad (FUCAI), centrada en la memoria histórica de las violencias padecidas por los pueblos indígenas del Trapecio Amazónico, en la Amazonía colombiana, y los que se asientan en Pebas, en la Amazonía peruana, su resistencia a las mismas y su poder pacífico transformador. El estudio fue auspiciado y apoyado por el Centro Nacional de Memoria Histórica. En esta, indígenas tikuna, cokama y yagua, en el Trapecio Amazónico colombiano,

\section{Abstract}

The preliminary findings of research carried out on behalf of the Fundación Caminos de Identidad (FUCAI) are brought together in this article: the historical memory of violence experiences, and their resistance, and the nonviolent transformative power of the indigenous peoples of the Amazonic Trapezia in Colombia and of the Peba area of the Peruvian Amazon. During the research process participants from the Tikuna, Cokama and Yagua peoples in the Amazonic Trapezia in Colombia, and from the Bora, Okaina, Murui-Muiane and Yagua groups

doi:10.11144/Javeriana.PAPO19-2.mrpp

* Artículo de Investigación. Este artículo recoge hallazgos preliminares de la investigación: "Memoria histórica de las violencias padecidas por los pueblos indígenas del Amazonas, su resistencia y su poder pacífico transformador. Cerrando el canasto de la barbarie, para poder abrir el de la esperanza, la armonía. y la abundancia", desarrollada por el equipo investigador de FUCAI con la colaboración del Centro de Memoria Histórica -CMH-. El equipo estuvo integrado por Esperanza Hernández Delgado, investigadora principal, Fernando Acosta Zapata, co-investigador y Ruth Chaparro Gómez, asesora especializada.

** Candidata a doctora en Paz, Conflictos y Democracia de la Universidad de Granada, España. Magíster en Estudios Políticos de la Pontificia Universidad Javeriana. Docente e investigadora para la paz. Correo electrónico: esperanza.construcciondepaz@gmail.com 
y bora, okaina, murui - muinane y yagua, en Pebas, Perú, dan cuenta de los significados que atribuyen a la memoria, sus heridas aún sin cicatrizar, los significados, expresiones y logros de su resistencia y su poder pacífico transformador que en sus palabras, les ha permitido hacer tránsito perfectible de 'víctimas a sobrevivientes victoriosos'.

\section{Palabras clave:}

Amazonia; Trapecio Amazónico; Pebas; pueblos indígenas; memoria histórica; resistencia indígena; poder pacífico transformador

\section{Cómo citar este artículo:}

Hernández, E. (2014). Memoria, resistencia y poder pacifico transformador de pueblos indígenas de las Amazonías colombiana y peruana. Papel Político, 19(2). pp. 497-525. http://dx.doi.org/10.11144/Javeriana.PAPO 19-2.mrpp in the Peba Amazon in Peru, became aware of the importance that they give to memory, the wounds that have not yet scarred over, and their meanings, along with the expression and reach of their resistance to violence, and the nonviolent transformative power of their words which they say have enabled them to make a complete transition from 'victims' to 'victorious survivors'. The work was supported and carried out under the auspices of the National Center for Historical Memory.

\section{Keywords:}

Amazon; the Amazonic Trapezia; Peba; indigenous peoples; historical memory; indigenous resistance; non-violent transforming power 
"El pasado se vuelve memoria cuando podemos actuar sobre él en perspectiva de futuro" Sánchez Gómez G. (2003), Guerra, memoria e historia.

\begin{abstract}
"Para nosotros los Yaguas, los poquitos que quedamos, es de la mayor importancia dar a conocer a otros las violencias que hemos padecido, para mostrarle a Colombia y al mundo entero lo que pasó con nosotros, y porque nos siguen excluyendo por ser minorías étnicas" ${ }^{11}$.
\end{abstract}

\title{
Presentación
}

En forma generalizada, el departamento del Amazonas se percibe como diversidad étnica y cultural, selva exuberante, importante reserva ecológica del planeta y biodiversidad (Navia, 1995, pp. 16-17; González, 1996, p. 31; Sting y Dutilleux, 1989, p. 20; Pineda, 2011, p. 356; Hildebrand y Brackelaire, 2012, pp.12-29). También como escenario de abundantes fuentes hídricas, grandes y caudalosos ríos, como el Amazonas y por su condición especial de triple frontera², en la parte del mismo que se conoce como: ‘Trapecio Amazónico' (Navia, 1995, p. 17; Donadio, 1995). Diversas expresiones alusivas a la Amazonía colombiana así lo evidencian: "tierra de los mil matices del verde", "pulmón del mundo" y "patrimonio universal" (Navia, 1995, pp.16-19). Esta mirada ha ido dejando atrás, la que primó en el pasado mediato, que definía este departamento y la Amazonía colombiana en general, como territorio salvaje, inhóspito, malsano y peligroso (Navia, 1995, p. 16).

Una mirada más integral del Amazonas registra también otras realidades, desconocidas o insuficientemente conocidas en el contexto nacional. Este departamento ha sido escenario de diversas y sucesivas violencias ${ }^{3}$ : el genocidio perpetrado contra los pueblos uitoto, bora, muinane y okaina, durante las dos primeras décadas del siglo XX, por quienes personificaron la violencia conocida como: 'la cauchería' (CAAAP y IWGIA, 2012; Donadio, 1995, pp. 15-47); el movimiento migratorio forzado de algunos indígenas de estos pueblos al Perú (Información recogida durante trabajo de campo, abril de 2013); una invasión extranjera en 1932 que desató una guerra internacional con el Perú (Donadio, 1995); y la violencia generada por diversas iniciativas de economía extractiva en torno al caucho, la madera, las pieles y los animales, soportadas en la esclavización,

\footnotetext{
${ }^{1}$ Manifestación de los indígenas yaguas durante el trabajo de campo realizado en la comunidad de la Libertad - Trapecio Amazónico.

${ }^{2}$ El territorio del departamento del Amazonas, identificado como Trapecio Amazónico integra la triple frontera que conforman las Amazonías colombiana, peruana y brasilera. No obstante, se destaca que en el imaginario de los pueblos indígenas que se asientan allí, estas fronteras no existen, dado que asumen este territorio en forma integral, que a su vez, asumen como propio y ancestral. ${ }^{3}$ Los pueblos indígenas objeto de este informe, identificaron dentro de ellas: 'la caucheria', la guerra entre Colombia y Perú, la evangelización, la explotación de la madera, las pieles y los animales, el narcotráfico, y el conflicto interno armado.
} 
explotación, negación e invisibilización de dichos pueblos (Información recogida durante trabajo de campo, abril de 2013). A ellas se agregan las violencias del narcotráfico, el conflicto armado, la minería y por supuesto, la violencia estructural que se refleja en sus condiciones de vida (Información recogida durante trabajo de campo, abril de 2013)

El desconocimiento en mención, se extiende también a la resistencia que ha permitido a estos pueblos sobrevivir en medio y a pesar de las violencias y a su poder pacífico transformador que ha posibilitado, de manera perfectible, su transición de víctimas a 'sobrevivientes victoriosos'4, tal como ellos mismos lo expresan.

En el marco de la investigación realizada, indígenas de los pueblos tikuna, yagua y cokama en el Trapecio Amazónico de Colombia, y bora, okaina, murui muinane y yagua, en Pebas, en la Amazonía Peruana, se remontaron a un pasado lejano, hará unos cien años, para reconstruir colectivamente la memoria de las violencias padecidas, su resistencia a las mismas y su poder pacífico transformador. En dicho ejercicio, Cauchería, evangelización, explotación de maderas, pieles y animales, conflicto armado y narcotráfico, fueron las violencias identificadas por los pueblos mencionados. Si bien cada una de ellas representa una modalidad específica con características propias y han hecho presencia en momentos históricos diferentes, se hizo visible una constante que las articula a todas: la exclusión y el racismo que culturas, sectores y actores hegemónicos o dominantes han ejercido sobre minorías indígenas y que galopan sobre la errada convicción de superioridad étnica, cultural, social y económica frente a los mismos.

En consideración de algunos analistas, a lo largo de la historia de este país el departamento del Amazonas se ha mantenido en el olvido y aún no se ha registrado su total integración a la nación (Donadio, 1995, p. 13; Hildebrand y Brackelaire, 2012, p. 27). En similar sentido, los pueblos indígenas del Trapecio Amazónico expresaron que no se sentían reconocidos y que otro tanto ocurría con su historia y las violencias padecidas, a su juicio desconocidas o insuficientemente conocidas (Información recogida en trabajo de campo. Abril de 2013). Aseguraron que era necesario, importante y reparador, avanzar hacia su real reconocimiento como pueblos y su articulación en el presente de este país y en su historia incompleta, mediante políticas interculturales que respetando, la diferencia, permitan construir formas de relación armónicas y democráticas.

Para responder a esta realidad, la Fundación Caminos de Identidad (FUCAI), una organización no gubernamental, con una trayectoria de más de veinte años realizando el acompañamiento a pueblos indígenas de la Amazonía colombiana, formuló un proyecto de investigación que contó con el apoyo del Centro de Memoria Histórica (CMH). Este artículo se centra en los hallazgos preliminares de la investigación en mención, presentados por FUCAI al CMH, mediante informe de noviembre de 2013.

\footnotetext{
${ }^{4}$ Expresión utilizada por los pueblos indígenas del Amazonas.
} 


\section{Sobre la investigación realizada}

Esta investigación se identifica como investigación para la paz ${ }^{5}$, porque la temática que aborda representa uno de sus ámbitos de estudio. Las víctimas, sus derechos, la memoria histórica dentro estos y su atención integral, al igual que sus actos de resistencia indígena y su poder pacífico transformador, son aspectos relevantes para la construcción de la paz. Se ubica además en un ámbito transdisciplinar dado que se nutre del aporte de diversas ciencias sociales: ciencia política, antropología, arqueología, historia y sociología, entre otras. A su vez, espera que sus hallazgos contribuyan a las mismas. Es también intercultural. Reconoce y respeta la diferencia y a su vez, construye a partir de la misma.

En esa perspectiva, el conocimiento que genera es producto de la articulación de saberes propios y ancestrales de los pueblos indígenas con saberes académicos no indígenas e indígenas. La interculturalidad de la investigación se plantea desde la conformación del equipo investigador que contó, para su mayor fortaleza, con un co-investigador indígena. También en la metodología se propuso el uso de instrumentos de recolección de información de la academia occidental y a su vez, aplicó instrumentos propios de los pueblos indígenas.

Se empleó en la metodología de la investigación acción participante (IAP), por considerarla como la más adecuada para el desarrollo de su objeto y el abordaje de los cualificados actores ${ }^{6}$ que representan el eje central de la investigación. Los académicos generadores o practicantes de la IAP han utilizado expresiones con las que han intentado recoger los significados e intencionalidades de esta metodología: "dar poder", “conciencia crítica”, "transformación”, “concientización”, “diálogo”, “acción social”, “empoderamiento” y “participación”, entre otros (Salazar, 1992, p. 142).

Constituyó el objeto de esta investigación: posibilitar que los pueblos indígenas del Amazonas, de manera participativa e incluyente, reconstruyeran la memoria histórica de las violencias que han padecido, su victimización por cuenta de las mismas, el múltiple impacto por ellas generado y el eje articulador entre estas violencias; hacer visible esta memoria histórica; y facilitar su articulación dentro de la reconstrucción de la memoria histórica nacional. De igual forma, reconocer el poder comunitario, pacífico y transformador de dichos pueblos, con el que han dado respuesta a las violencias mencionadas, haciendo tránsito, como ya se ha mencionado, de víctimas a 'sobrevivientes victoriosos?7, y alcanzando logros significativos y perfectibles, en la perspectiva de que

\footnotetext{
${ }^{5}$ La investigación para la paz puede ser comprendida como una modalidad de investigación de la ciencia política, que indaga en el pasado y el presente en perspectiva de futuro, sobre las condiciones necesarias para construir la paz. Para mayor información, ver: Galtung J. (1995).

${ }^{6}$ Pueblos indígenas de las Amazonías colombiana y peruana.

${ }^{7}$ Así lo expresan textualmente los pueblos indígenas del Amazonas.
} 
dicho reconocimiento contribuya, al igual que la reconstrucción de la memoria, a su proceso de reparación integral.

\section{Contexto geográfico}

El contexto de la investigación estuvo representado por cuatro escenarios: la Amazonía Latinoamericana, la Amazonía colombiana, el Trapecio Amazónico y Pebas en la Amazonía peruana.

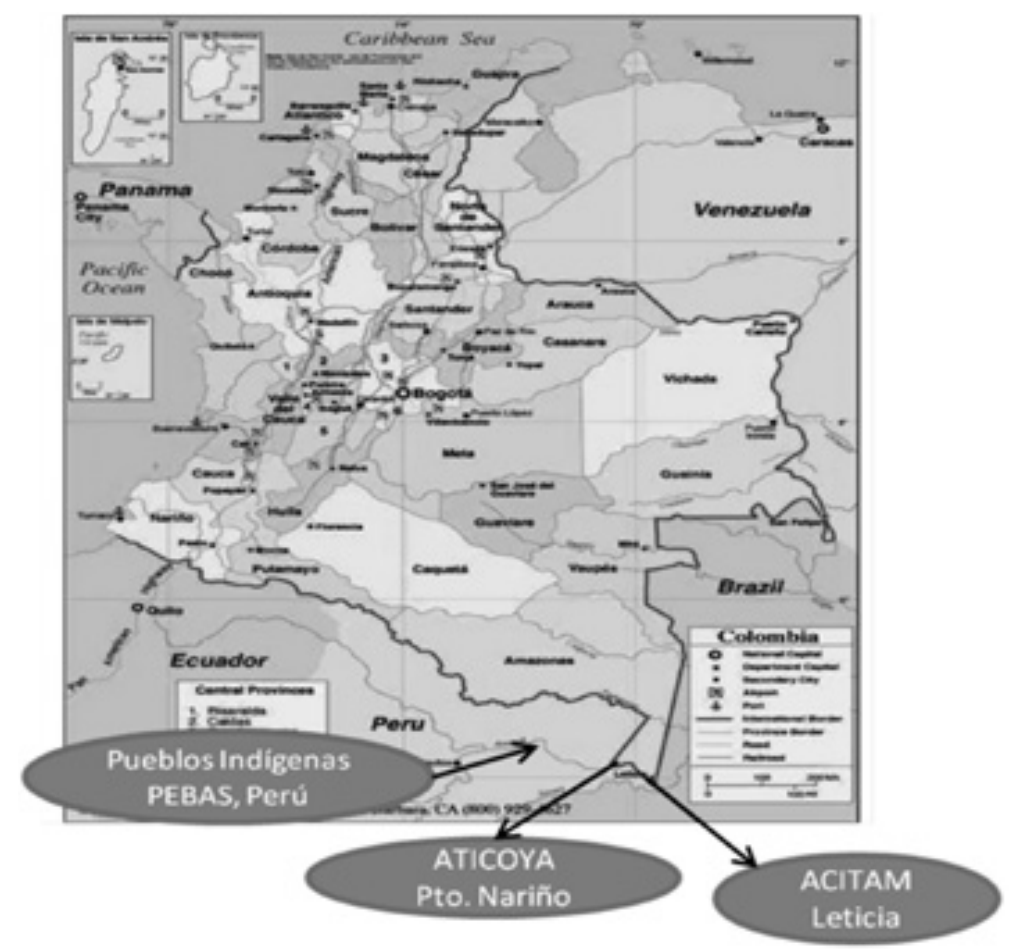

La Amazonía Latinoamericana. Fuente: Fernando Acosta de FUCAI.

América Latina fue el último continente ocupado por el Homo Sapiens (Goés, 2011, p. 41) y según estimativos coincidentes, este ha estado habitado desde hace 11.000 años (Goés, 2011, p. 42). Se considera que desde entonces hasta el siglo XVI, se mantuvo aislado (Goés, 2011). Esta Amazonía se define como cuenca o bioma. La cuenca se delimita por el río Amazonas y sus afluentes y el bioma por la selva húmeda tropical que la atraviesa (Goés, 2011, p. 28). Este gran río Amazónico, reconocido como el más profundo, caudaloso y ancho del mundo (Navia, 1995, p. 23; Sting y Dutilleux, 1989, p. 9), constituye la cuenca más grande que existe, representa un gran reservorio de agua dulce y biodiversidad y ocupa $44 \%$ de la superficie de América Latina y más del $5 \%$ de la superficie terrestre del planeta (Hildebrand y Brackelaire, 2012, pp. 27-28). 
Se estima que la cuenca en mención cubre aproximadamente entre 7.3 y 7.8 millones de kilómetros cuadrados, siendo compartida por nueve países: Bolivia, Brasil, Colombia, Ecuador, Guyana, Perú, Venezuela, Guyana Francesa, y Surinam (Hildebrand y Brackelaire, 2012, p. 29). En ella se asientan más de 400 grupos étnicos que alcanzan una población aproximada de 1.000.00o indígenas (Hildebrand y Brackelaire, 2012, p. 27); produce una quinta parte del oxígeno del mundo; alberga una tercera parte de las formas de vida conocidas y está estrechamente ligada a los pueblos indígenas que la habitan, sus cosmovisiones, formas de vida y subsistencia (Hildebrand y Brackelaire, 2012, p. 28).

Las primeras colonizaciones en la Amazonía se registran desde el siglo XVI y a partir de las mismas, también se hace visible su impacto destructivo sobre esta región, los pueblos que la habitan y sus recursos naturales (Hildebrand y Brackelaire, 2012, p. 26). Así lo evidencia la desaparición de setenta por ciento (70\%) de la población indígena y la pérdida de dieciocho por ciento (18\%) del bosque y de buena parte de la biodiversidad (Hildebrand y Brackelaire, 2012). También, la generación y difusión de la percepción negativa, peyorativa y descalificativa del indígena que lo identifica desde entonces como salvaje, ignorante, incapaz y obstáculo para el desarrollo (Hildebrand y Brackelaire, 2012).

En las últimas tres décadas la Amazonia se ha hecho más visible (Navia, 1995, p. 16; Hildebrand y Brackelaire, 2012, pp. 17-28). En parte por el deterioro ambiental del planeta que representa una amenaza para la humanidad y por los intereses económicos nacionales y transnacionales que identifican en sus recursos naturales, importantes fuentes de explotación económica (Hildebrand y Brackelaire, 2012). En ese contexto y en forma contradictoria, la Amazonia es reconocida como escenario de interés prioritario para el equilibrio y la resiliencia ambiental y la supervivencia del planeta; pero al mismo tiempo, continua siendo objeto de sobreexplotación y de diversas modalidades de degradación: agroindustria, hidroeléctricas, madereras, minería y ganadería extensiva (Hildebrand y Brackelaire, 2012, p. 26).

\section{La Amazonía colombiana}

En el contexto continental, la Amazonía colombiana se ubica en el noroeste Amazónico y se conforma en torno a diversas cuencas hidrográficas: Alto Orinoco, Alto río Negro, ríos Caquetá y Putumayo y un trayecto de 117 kilómetros sobre el río Amazonas, conocido como ‘Trapecio Amazónico’ (Pineda, 2011, p. 356). Una parte de la misma está constituida por bosques tropicales y cuencas y se conoce como Alta Amazonía; y otra, por el piedemonte de la cuenca del río Amazonas (Pineda, 2011). Se estima que ocupa 33\% del territorio nacional (Pineda, 2011) y representa 6\% del bioma Amazónico (Hildebrand y Brackelaire, 2012, p. 29). Como bio-región abarca 483.119 kilómetros cuadrados que corresponden a 43\% del territorio colombiano y comprende seis departamentos: Amazonas, Caquetá, Guainía, Guaviare, Putumayo y Vaupés. Su población equivale al 2.82\% de la nacional y se estima en 1.300.00o habitantes (Hildebrand y Brackelaire, 2012, p. 30). 
En su zona occidental de piedemonte, en los departamentos del Caquetá, Guaviare y Putumayo, se han registrado acelerados procesos de colonización y existe una mayor participación en las actividades económicas con el centro del país. Su zona oriental, en los departamentos del Amazonas, Guainía y Vaupés, cuya población es en su mayoría indígena y dispersa, mantiene muy limitados contactos con el centro del país (Hildebrand y Brackelaire, 2012).

La Amazonía colombiana alberga 67 pueblos indígenas que representan $71 \%$ del total de estos pueblos en el país. 47\% de ellos se ubican en la Amazonía occidental y el restante 53\% en la oriental (Hildebrand y Brackelaire, 2012, p. 36). En su gran mayoría, se asientan en los departamentos del Amazonas, Guainía y Putumayo (Hildebrand y Brackelaire, 2012) y sus poblaciones no son numerosas, a excepción del pueblo tikuna en el Trapecio Amazónico (Pineda, 2011, pp. 356-357). Esta región ha soportado el impacto de iniciativas económicas extractivas, nacionales, extranjeras o transnacionales, que como una constante han instaurado la explotación de los pueblos indígenas y en algunos casos, su esclavización y el genocidio, como en los tiempos de 'la caucheria' y 'la Casa Arana', en diversos escenarios del territorio que en la actualidad se conoce como 'Resguardo Indígena Predio Putumayo' (Pineda, 2011, p. 357).

En su historia reciente, la cuenca Amazónica colombiana ha sido consideraba como la mejor conservada, quizás por representar la de más difícil acceso e incluso, a dos años de la conferencia de Río de Janeiro en 1992, cuando se registraban los primeros llamados frente a las amenazas sobre la biodiversidad, esta cuenca era considerada como tesoro natural y cultural (Hildebrand y Brackelaire, 2012, pp. 11-12). Sin embargo, no puede desconocerse que el boom de los cultivos ilícitos en la década de 1980 posibilitó la penetración de la selva por el oriente y de igual manera, la explotación de recursos naturales que generó el ingreso de petroleras y empresas mineras, así como el incremento de la colonización (Hildebrand y Brackelaire, 2012). Se agregarían a los anteriores, como impacto negativo sobre esta Amazonía, el cambio climático, la deforestación y diversas contaminaciones (Hildebrand y Brackelaire, 2012, p. 13). En la actualidad, una de las mayores amenazas la representan los permisos de explotación minera que llegan a cubrir casi toda el área oriental de la Amazonía colombiana (Hildebrand y Brackelaire, 2012, p. 15).

\section{El Trapecio Amazónico}

Se ubica en el extremo sur del departamento del Amazonas y reúne la condición especial de triple frontera entre Perú, Colombia y Brasil. La delimitación de fronteras ha sido muy relevante allí. Desde el siglo XIX, este territorio fue objeto de disputa fronteriza entre Colombia y Perú (Donadio, 1995, p. 13; p. 49). Si bien en 1922 esta diferencia pareció zanjada mediante el Tratado Lozano - Salomón, suscrito entre los dos países para dirimir dichas diferencias, posteriormente este conflicto alcanzó su máxima expresión 
en septiembre de 1932 cuando se registró una invasión a Leticia por parte de hombres armados del Perú, acontecimiento que se convirtió en el detonante del conflicto armado internacional desatado entre los dos países (Donadio, 1995, pp. 109 -119).

En el Trapecio Amazónico se asientan indígenas de los pueblos tikuna, cokama y yagua, el primero de origen brasilero, el segundo y el tercero de origen peruano (Información recogida durante trabajo de campo, abril de 2013). Estos pueblos indígenas perciben el área de triple frontera de manera integral, dado que la identifican como su territorio ancestral y en el caso de los abuelos y las abuelas, les es difícil comprender la existencia de fronteras.

\section{Pebas}

Es uno de los cuatro distritos de la Provincia de Mariscal Ramón Castilla, en el Departamento de Loreto, en Perú. Se ubica en la Amazonía de ese país y representa la segunda localidad, después de Iquitos, en dicha región. Está integrado por 19 comunidades $^{8}$ que se extienden sobre el río Ampiyacu o en proximidad con el mismo.

En él se asientan diversos pueblos indígenas ${ }^{9}$ y entre ellos, los bora, murui miunane, okaina y yagua, protagonistas de la investigación en mención, en este escenario geográfico. Los tres primeros comparten algunos rasgos comunes: sus orígenes se ubican en Colombia, específicamente en La Chorrera, en el departamento del Amazonas; sus antepasados fueron víctimas de la violencia cauchera y el genocidio perpetrado por los actores de la misma y llegaron al Perú, producto de un movimiento migratorio forzado, generado por esta modalidad de violencia y la guerra internacional que vinculó a Colombia con Perú entre 1932 y 1933.

\section{Ejes conceptuales que soportan este artículo}

Memoria histórica, resistencia y poder pacífico transformador, representan los conceptos clave que soportan este artículo. El primero, comprendido como derecho individual y colectivo a la verdad de víctimas de la violencia (Hernández, 200o); el segundo como mecanismo de lucha y de defensa de los pueblos indígenas (Hernández, 2004; 2009; 2012); y el tercero como desarrollo de capacidades y potencialidades que hacen posible el empoderamiento pacifista de pueblos, comunidades y sectores poblacionales en medio, o a pesar de las violencias y la transformación de la realidad (Muñoz, 2001; Comins y Muñoz, 2013).

$\mathrm{Al}$ abordar la memoria histórica, vale la pena destacar que tratándose de violencias en los ámbitos social o político, no hay pasado que no condicione la vida de los pueblos, comunidades y sectores poblacionales que las padecen. Por esta razón, coincidimos con

\footnotetext{
${ }^{8}$ Dentro de ellas: Anco-Colombia, Brillo Nuevo, Puerto Izango, Nuevo Perú, Nueva Esperanza, Nuevo Porvenir, Estirón del Cusco, uitoto de Estirón, yaguas, Ronda, El Vergel, El Progreso, Loma Linda, La Libertad, San José del Río, Nuevo Jardín, la Milagrosa, Palmeras, Uitoto de Pucaurquillo y Triunfo. ${ }^{9}$ tikuna, bora, orejones, uitoto, okaina, muruy muninane, yagua.
} 
quienes afirman que esta modalidad de memoria es producto del impacto de las guerras, los conflictos armados internos y las dictaduras; de los requerimientos de comisiones de la verdad, regímenes de transición y periodos de post conflicto (Sánchez, 2006, pp.15-17) y esencialmente de las necesidades y demandas de las víctimas, factor que se agregaría a los anteriores. Se destaca la importancia de la memoria, especialmente en países con violencias arraigadas, recurrentes y prolongadas, pues como afirmaron los obispos de Guatemala en Centroamérica, en el proyecto de recuperación de la memoria histórica (REMI), “mientras no se conozca el pasado la heridas seguirán abiertas" (Hernández, 2000, p. 29).

En este artículo y en la investigación que lo soporta, se asume la memoria histórica en su 'dimensión liberadora'10, como derecho de los pueblos del Amazonas a la verdad y con el propósito de aportar a la reparación, largamente deseada por los mismos. También como mecanismo de no repetición de las violencias y requerimiento del proceso de construcción de la paz en Colombia. Se facilitó la reconstrucción colectiva de la memoria para que los pueblos en mención pudieran reasumir y resignificar el pasado y al mismo tiempo, fortalecer su identidad y su confianza en el futuro y en sus procesos comunitarios.

En cuanto a la resistencia indígena, es su dimensión no violenta de la que se ocupa este artículo. En esa perspectiva, puede ser entendida como proceso colectivo de lucha y de defensa de mínimos vitales: la vida en su dimensión más amplia, la cultura, el territorio, la autonomía y los procesos comunitarios, entre otros; mediante métodos y mecanismos propios que no admiten el recurso a la violencia (Hernández y Salazar, 1999; Hernández, 2004; 2006; 2009; 2012).

Desde el arribo de los españoles colonizadores en los siglos XV y XVI, en forma ejemplarizante mediante su resistencia ancestral, los pueblos indígenas de Colombia han logrado pervivir a las distintas violencias que se han perpetrado contra ellos en sus territorios ancestrales (Hernández, 2004; 2006, p. 179; 2012, p. 80; pp. 103-105; p. 110). Reconocer esta resistencia es importante porque representa una parte vital de su historia y de manera especial en el marco de un proceso de reparación integral porque posibilita su reconocimiento y auto-reconocimiento, no solo como víctimas de las violencias sino también como actores con capacidad de lucha en defensa de los derechos que son inherentes a su condición de pueblos.

Respecto del concepto de poder pacífico transformador, representa una categoría académica reconocida a principios de este siglo dentro de las disciplinas que se dedican al estudio de la paz (Muñoz, 2001; Muñoz, Molina, Herrera y Sánchez, 2005, pp.

\footnotetext{
${ }^{10}$ Gonzalo Sánchez identifica dos dimensiones de la memoria, una liberadora y otra paralizante. La primera, posibilita relacionar acontecimientos del pasado con los del presente y sus estructuras, rescatando lo importante y desechando lo inútil. La segunda genera y dinamiza un nuevo ciclo de violencia, muchas veces en nombre de la memoria (Sánchez, 2006, p. 17).
} 
124-125; Comins y Muñoz, 2013); y a su vez, una realidad propositiva y ejemplarizante, evidenciada en procesos de pueblos, comunidades, sectores poblacionales y colectivos de diversa naturaleza (Hernández, 2012).

La investigación para la paz y la historia de la paz han ofrecido abundantes evidencias que permiten afirmar que los seres humanos y sectores mencionados, no están irremediablemente atados a la violencia; dado que se anida en todos ellos un poder pacífico y transformador (Hernández, 2012). Este poder hace posible lo aparentemente imposible: proteger los mínimos vitales ya mencionados, en contextos de alta violencia; la supervivencia de los pueblos y sus culturas a pesar de la barbarie, el genocidio y niveles inimaginables de degradación; la movilización exitosa de la sociedad civil que logra poner fin a dictaduras; el fortalecimiento de los pueblos y sus procesos comunitarios a pesar de violencias recurrentes, como en el caso de los indígenas del Trapecio Amazónico y de Pebas en la Amazonía peruana; resistencias no violentas que hacen rupturas en las lógicas de la guerra; y resolución y transformación pacífica de conflictos armados de larga data, entre otros (Muñoz, 2001; Muñoz, Molina, Herrera y Sánchez, 2005; Muñoz, Bolaños,2011; Muñoz, Jimenez, 2012; Comins y Muñoz, 2013; Hernández, 2008; 2009; 2011; 2012; Lederach, 2008).

Este poder puede ser comprendido como el desarrollo de capacidades y competencias, individuales y colectivas, para asumir y superar el impacto de las violencias, resolver pacíficamente los conflictos, hacer una transición de violencias destructivas a acuerdos constructivos, satisfacer necesidades esenciales, y 'hacer tránsito de víctimas a sobrevivientes victoriosos', apropiando la expresión textual de los pueblos indígenas en mención, entre otros. Aspectos todos ellos que representan construcción de paces perfectibles e inacabadas (Comins y Muñoz, 2013).

\section{Hallazgos preliminares}

Se relacionan a continuación hallazgos preliminares relevantes de la investigación en referencia, relacionados con la memoria histórica, la resistencia y el poder pacífico transformador de los pueblos asentados en el Trapecio Amazónico y en Pebas.

\section{En relación con la memoria histórica}

En las culturas de los pueblos indígenas mencionados, la memoria representa uno de los principales mecanismos de preservación de las mismas, el fortalecimiento de la identidad y un ejercicio de resistencia (Información suministrada durante el trabajo de campo, abril a septiembre de 2013).

La memoria es importante para poder reconstruir en su totalidad todas las costumbres, las violencias vividas por nuestros antepasados y a partir de allí, poder nosotros seguir 
fortaleciéndonos en la protección de nuestras culturas tradicionales y en la resistencia de nosotros los pueblos indígenas. (Afirmación del pueblo tikuna en minga de pensamiento de trabajo de campo, abril de 2013)

Son diversos, profundos y coincidentes los significados que otorgan estos pueblos indígenas a la memoria y en ellos recobra vigencia lo señalado por algunos analistas: “[...] la memoria es, en sentido profundo, una forma de resistencia a la muerte, a la desaparición de la propia identidad" (Sánchez, 2006, p. 21). La investigación evidenció que estos pueblos mantienen viva la memoria colectiva sobre las violencias que han padecido, su resistencia y su poder pacífico transformador; al igual que siguen abiertas las heridas causadas por las mismas y de manera especial, las que dejó a su paso la violencia de la cauchería (Información suministrada durante el trabajo de campo, abril a septiembre de 2013).

\section{La memoria histórica desde la mirada y las voces de los pueblos del Trapecio Amazónico}

La memoria no es ajena a los pueblos tikuna, cokama y yagua del Trapecio Amazónico, por el contrario, estos pueblos le otorgan especial importancia y diversos significados. Dentro de los mismos, la memoria se encuentra estrechamente vinculada con la recuperación y el fortalecimiento de su identidad cultural, especialmente frente a nuevas generaciones, las presentes y las que vendrán. Se relaciona también con la defensa del territorio (Información suministrada durante el trabajo de campo, abril a septiembre de 2013).

$\mathrm{Su}$ percepción de la memoria establece un hilo conductor entre el pasado, el presente y el futuro, como un pasado que explica el presente y cuyo reconocimiento permite fortalecer la identidad. En sus palabras, "la memoria de nuestros antepasados, tatarabuelos, abuelos y padres que fueron explotados, discriminados y despojados, permite entender el hoy y el futuro" (Afirmación de pueblo yagua, en minga de pensamiento de trabajo de campo, abril de 2013).

Para los pueblos en mención, la memoria colectiva del pasado también tiene un significado de liberación y sanación frente a dolores del ayer causados por las violencias. Se destaca que para los mismos no es relevante el tiempo que haya transcurrido desde el momento que fueron victimizados, porque como se ha manifestado anteriormente, estos recuerdos y dolores se mantienen vivos o intactos en su memoria individual y comunitaria (Información recogida en trabajo de campo, abril de 2013).

En igual medida, esta memoria es percibida como mecanismo de exigencia de derechos, especialmente de reparación, por los daños causados por las violencias y con mayor énfasis, por aquellos generados por la violencia cauchera. También se perciben como medio para impedir la repetición de las violencias, significado que expresan como: “alerta 
que permite estar organizados y preparados para que el pasado de violencia no vuelva a repetirse" (Expresión del pueblo tikuna, trabajo de campo, abril de 2013).

Es relevante también, el significado que otorgan a la memoria como mecanismo de resistencia o de lucha frente a violencias que han padecido a lo largo de la historia, como la exclusión y el racismo (Información suministrada durante trabajo de campo, abril de 2013).

\begin{abstract}
Para nosotros los yaguas, los poquitos que quedamos es de mayor importancia para mostrarle a Colombia y al mundo entero lo que pasó con nosotros, porque nos siguen excluyendo por ser minorías étnicas. (Afirmación del pueblo yagua en minga de pensamiento de trabajo de campo, abril de 2013)
\end{abstract}

Para estos pueblos, la memoria está relacionada con la violencia porque surge como respuesta a la misma, ya sea en términos de verdad con respecto a la manera en que ocurrieron los hechos de violencia, sus perpetradores y los repertorios de esas violencias (Información suministrada durante trabajo de campo, abril de 2013). No obstante, también está estrechamente vinculada con la vida y la esperanza, el respeto y la protección.

\title{
La memoria histórica desde la mirada y las voces de los pueblos de Pebas, Amazonía Peruana
}

Para los pueblos que se asientan en Pebas, al igual que para los del Trapecio Amazónico, la memoria histórica es comprendida como articulación del pasado con el presente y el futuro (Información suministrada durante trabajo de campo, abril de 2013). Equivale a reencontrarse con las violencias del ayer para fortalecerse en el presente, manteniendo la cultura y las tradiciones. Esta memoria no asume los acontecimientos del pasado como realidad inamovible, dado que se remonta al pasado para reconstruir en el momento actual la ruptura generada por las violencias de entonces y al mismo tiempo fortalecerse de cara al futuro.

\section{[...] cuando una cosa se desase, se derrumba, se cae, entonces se vuelve a armar de nuevo; eso quiere decir reconstruir, entonces eso es lo que estamos tratando de hacer con las historias de nuestros abuelos, es igual que también cuando nosotros soñamos que [...] por decir tú tienes un sueño y al segundo día te levantas, te despiertas y te recuerdas de esa memoria [...]. (Entrevista con Santiago Yahuarcani durante trabajo de campo, septiembre de 2013)}

En sus cosmovisiones - un elemento central en la elaboración de su memoria- lo representan sus plantas sagradas, especialmente el tabaco, al que asignan esa capacidad reparadora o reconstructora que hace posible empezar de nuevo, aunque no sea en el lugar de origen sino en aquel a donde tuvieron que desplazarse para sobrevivir. 
[...] recordar en bora es Itabe, en general es como una planta de tabaco caído que vino a retoñar en otros lugares que no tienen el mismo guano de su tierra natal. Respondemos así porque nosotros como bora dicen que somos creados por el tabaco, la coca y la yuca dulce, las tres plantas que yo he mencionado, entonces es como que allá le han destruido, primeramente nos vinimos a organizar y luego han venido ya a otras tierras [...]. (Información del pueblo bora, en minga de pensamientos en trabajo de campo en Pebas, septiembre 2013)

Estos pueblos se reconocen como víctimas y admiten llevar a cuestas un dolor generado por acontecimientos ocurridos hace más de cien años, específicamente por la violencia cauchera; que a su vez han mantenido en la memoria al transmitirlo desde el relato de los y las abuelas, de generación en generación (Información recogida en trabajo de campo, septiembre de 2013). En este contexto, reconocen la importancia de la memoria histórica. También se identifican como pueblos pacíficos y aclaran que no hacen memoria para vengarse sino para demandar derechos y poder acceder, por esta vía, a una reparación integral, largamente deseada. También para proteger su identidad indígena que expresan literalmente como: 'raíces indígenas', especialmente para las generaciones que han venido después y las que vendrán mañana.

La memoria histórica para los bora es reconstruir el pasado violento manteniendo nuestras tradiciones, tratando de fortalecer nuestras tradiciones, la cultura tradicional dentro de la Amazonia peruana. Seguimos hasta ahora practicando, enseñando a la niñez como docentes en otras escuelas, estamos practicando las danzas e inclusive las comidas típicas, o sea todas esas cosas, todavía seguimos haciéndolo, teniendo en cuenta todo eso acá en la Amazonia [...]. (Información suministrada por pueblo bora en minga de pensamiento durante trabajo de campo en Pebas, septiembre de 2013).

\section{En relación con las violencias que los han afectado}

Este aparte registra las violencias identificadas por los pueblos indígenas del Trapecio Amazónico y los de Pebas como aquellas que los han victimizado. También las coincidencias entre unos y otros al identificarlas, el carácter recurrente de las mismas, sus repertorios, los móviles que las generaron y dinamizaron, los actores que las perpetraron y los ejes articuladores de todas ellas.

Las violencias identificadas por los pueblos en mención pueden inscribirse en las categorías académicas de 'violencias directas' ${ }^{11}$ visibles, como el genocidio cauchero;

\footnotetext{
${ }^{11}$ Modalidad de violencia física, visible en su consumación ante cualquier ojo o lente, el acto deliberado de causar daño a las personas, los colectivos humanos, su integridad física, o los bienes.
} 
'violencia cultural'12; y violencias indirectas, invisibles, pero que también dejan huella, como la 'violencia estructural'13. Ellas se suceden unas tras otras en distintos tiempos, victimizan desde distintos métodos, causan múltiples impactos, muchos de ellos irreparables, se insertan en la memoria individual y colectiva y dejan heridas sin cicatrizar y también diversas enseñanzas o aprendizajes.

\section{Las violencias padecidas por los pueblos indígenas del Trapecio Amazónico} Coincidieron los pueblos tikuna, cokama y yagua al identificar las violencias que han padecido: la cauchería, la evangelización, las iniciativas económicas extractivas en torno a la madera, los animales y las pieles, el conflicto armado y el narcotráfico. Como se mencionó anteriormente, estas violencias estaban ancladas, fija y claramente en sus recuerdos, aunque algunas de ellas fueran distantes en el tiempo, como el caso de la cauchería. Las conocían aunque no las hubiesen vivido, por el método propio de transmisión de la cultura de los pueblos indígenas: los relatos de los abuelos o mayores que han mantenido viva la memoria, de generación en generación, tanto en lo relacionado con su historia y los aspectos propios de sus culturas, como con las violencias padecidas.

\section{La violencia de la cauchería}

Esta modalidad de violencia se ubica entre 1900 y 1905. El ejercicio de reconstrucción de memoria llevó a identificar la forma de vida de estos pueblos antes de que dicha violencia hiciera presencia en sus territorios que, para precisar, por entonces vivían en comunidad, unidad y solidaridad, regidos por la ley de origen, practicando los usos y costumbres, disfrutando de la abundancia en tranquilidad porque eran pueblos pacíficos y en un entorno territorial sin los límites que en la actualidad imponen las fronteras.

$\mathrm{Al}$ recordar la forma cómo los caucheros hicieron presencia en sus territorios, los denominaron como 'los patronos', e indicaron que se sirvieron del engaño y del dinero para acceder no solo a sus territorios, sino también a sus vidas. Mediante los mismos, les ofrecían implementos de trabajo, como cuchillos y hachas o artículos del hogar, como espejos o sencillamente dinero a cambio de ciertas cantidades de caucho que ellos debían recolectar semanalmente y en una proporción de intercambio totalmente inequitativa y de evidente explotación. Si bien algunos de estos pueblos ${ }^{14}$ tenían por costumbre huir ante la presencia de personas no indígenas, el engaño mediante estos intercambios

\footnotetext{
12 Modalidad de violencia que se soporta en la errada convicción de superioridad de unos sobre otros, ya sea por condiciones étnicas, raciales, de género, económicas.

${ }^{13}$ Modalidad de violencia definida como "aquella que impide a los seres humanos una vida mínimamente humana". Se genera en estructuras y relaciones de explotación, exclusión, injusticia y dominación. Es invisible el momento de su consumación al ojo o al lente, pero deja huellas.

${ }^{14}$ Siendo este el caso de los yagua.
} 
surtió el efecto deseado, logrando llamar su atención y la aceptación de su oferta, que para los indígenas equivalía a lo que conocían como 'trueque'.

Con respecto a los actores de esta violencia, identificaron a Julio Cesar Arana, cauchero peruano, a quien señalaron como el principal autor de la misma y por países, a Perú, Brasil, Inglaterra, Francia, Portugal, Italia y Colombia. A su vez, en cuanto a sus móviles, señalaron el carácter estrictamente económico de los mismos. Sus repertorios surgieron de manera fluida en la mirada colectiva del pasado y fueron identificados bajo diversas denominaciones: engaño, explotación, tortura, violación sexual, saqueo y migración forzada a países vecinos. Todos ellos develan negación, invisibilización, dominación, desprecio, es decir, racismo y exclusión de los pueblos en mención.

La reconstrucción de la memoria identificó también los impactos o las huellas de la cauchería. En forma coincidente, los pueblos reconocieron que el mayor impacto lo recibió su identidad cultural, dado que afectó su espiritualidad, sus formas propias de relación familiar, comunitaria y con la naturaleza, sus procesos organizativos, su lengua materna, su medicina y alimentación, sus usos y costumbres, así como sus prácticas culturales. A las anteriores se agrega la pérdida de autonomía y del territorio, la ruptura de su unidad, la afectación sobre su capacidad de resistencia, la pérdida de seres queridos, la desintegración familiar y el desarraigo generado por el desplazamiento interno y los movimientos migratorios forzados a países vecinos, pobreza, enfermedad, dependencia, humillación y trauma de las mujeres, jóvenes, adultas, abuelas y de hombres que fueron violados.

\section{La violencia de la evangelización}

Su surgimiento se ubica en el año 1800 para los cokama, en 1930 para los tikuna y entre 1940 y 1950 para los yagua. Estos pueblos coincidieron al reconocer que contaban con una cultura y una espiritualidad propia que les fue negada, invisibilizada y violentada desde el arribo de sacerdotes, religiosos o misioneros de la Iglesia Católica a sus territorios y a sus vidas. Desde ese momento, junto con los españoles colonizadores o 'invasores' ${ }^{15}$, los representantes de la Iglesia participaron de la postura hegemónica de los colonizadores que percibían al indígena como ‘bárbaro’ que debía ser civilizado (Castañeda, 2002).

$\mathrm{Al}$ respecto, debe tenerse en cuenta que desde la constitución política de 1886, hasta 1973, la religión católica fue reconocida constitucionalmente como la religión oficial y en el marco del concordato de 1887, se encomendó a los misioneros la educación e incorporación de los territorios indígenas (Pineda, 2011, p. 357). Solo hasta 1973, con la revisión del concordato, se suprimió el convenio de misiones y se adoptó la educación pública no misionera en los territorios mencionados (Pineda, 2011, pp. 357, 358); y luego,

\footnotetext{
${ }^{15}$ Denominación que otorgan algunos pueblos indígenas de Colombia a este momento histórico, bajo la consideración que fue una invasión. Entre ellos: los nasa y misak.
} 
con la carta política de 1991, se definió el Estado Colombiano como pluriétnico y pluricultural y se reconocieron importantes derechos a estos pueblos (Pineda, 2011, p. 357).

Esta violencia hizo presencia en sus territorios de la mano de la colonización española de los siglos XV y XVI y luego se consolidó y dinamizó con el manejo de la educación (Información recogida durante el trabajo de campo, abril de 2013). Respecto de sus actores, señalaron a la reina Isabel de España en los tiempos de expansión colonialista de este país, los sacerdotes y religiosas de la Iglesia Católica desde entonces y los pastores de las Iglesias Cristianas de hoy. Sobre su intencionalidad, mencionaron los intereses religiosos asociados a la hegemonía de la religión católica en su momento y los intereses económicos, asociados al saqueo de los recursos de sus territorios.

La violencia de la evangelización también registró métodos o repertorios propios. Ellos consistieron principalmente en imágenes, símbolos y libros religiosos. También en el temor y la culpa generada desde relatos bíblicos o instituciones como 'la inquisición', la presencia de misioneros en sus territorios y los obsequios que estos les entregaban. De igual manera, el aprovecharse de su 'inocencia' y de la carencia de organizaciones fuertes al interior de sus comunidades.

Señalaron sobre sus impactos, que el mayor de ellos fue la afectación sobre sus culturas y su identidad, realidad que se materializó de diferentes maneras: la prohibición a los pueblos de hablar la lengua materna, de practicar sus usos y costumbres, de vivir en desnudez o utilizar sus vestimentas propias; la satanización de su espiritualidad y su ritualidad; la imposición de otra religión y otra lengua, y los castigos aplicados por la renuencia a sencillas prácticas religiosas de la religión católica que les querían imponer a toda costa. A ellas se agregaron en algunos casos: la violación de niñas y la explotación de recursos económicos por parte de algunos religiosos.

\section{La violencia de las iniciativas económicas extractivas}

Otra violencia identificada fue la generada por iniciativas económicas extractivas, específicamente de maderas, animales y pieles. Ubicaron el surgimiento de aquella causada por la extracción de pieles en 1945, la de maderas en 1950 y la de animales en 1970. Como las anteriores violencias, esta también provocó un impacto significativo sobre estos pueblos, sus culturas, su identidad y especialmente su relación con la naturaleza.

Destacaron sobre la forma de vida que tenían antes que esta violencia hiciera presencia en sus territorios, que se desarrollaba en medio de una gran abundancia de recursos naturales, especies animales y vegetales, factor que favorecía la cacería, la recolección de frutas, la alimentación propia y la realización de sus rituales. En cuanto a sus actores, señalaron que no eran indígenas sino colonos o empresarios y su procedencia generalmente se ubicaba en otros departamentos de Colombia o en países vecinos e incluso en algunos casos, en países europeos, como España. 
Esta violencia logró consolidarse y dinamizarse por la coincidencia de diversos factores: la ambición y la codicia de sus actores; las necesidades de los indígenas, que facilitaron la aceptación de la explotación de sus recursos naturales en las condiciones planteadas por dichos actores; la corrupción de las autoridades competentes para ejercer control y en algunos casos, el desarrollo de investigación científica.

En cuanto a los métodos o repertorios de esta modalidad de violencia, identificaron nuevamente la explotación, la fuerza, la intimidación y el aprovechamiento de la necesidad, la inocencia y el limitado manejo del español por parte del indígena, su conocimiento de la selva y su estrecha convivencia con ella (Información suministrada durante el trabajo de campo, abril de 2013).

Con respecto a su impacto, identificaron la afectación sobre sus culturas, su identidad, su autonomía en la preservación de las especies y muy especialmente, su convivencia armónica con la naturaleza y el daño ecológico. Destacaron que en algunos casos se dejó de practicar la lengua materna, al igual que la caza, el cultivo de la tierra para el sostenimiento familiar y la práctica cultural de pedir permiso a los espíritus para aprovechar las especies de la selva. También agregaron a estos efectos: la explotación económica del indígena; su dependencia económica de los actores de esta violencia; la pérdida significativa de especies animales y vegetales; la escasez de animales para la caza; y que en algunos casos, se aprovechaba que los hombres estuvieran fuera de casa para violentar sexualmente a sus mujeres e incluso asesinar a los hijos que habían presenciado la violación.

\section{La violencia del narcotráfico}

Los cokama ubicaron la presencia de la misma entre 1975 y 1985, los tikuna en 1980 y los yaguas en 1978. Señalaron sobre su forma de vida antes que esta violencia llegara a sus territorios, que trabajaban para su sostenimiento de manera tradicional, esto es, mediante actividades agrícolas, la caza y la pesca. Tenían una vida tranquila, practicaban sus usos y costumbres y a su parecer, llevaban una vida sana. En cuanto a la manera como llegó a sus territorios, indicaron que vino de afuera, de países vecinos, de gentes de otras culturas que tenían formas de vida e intereses distintos a los suyos. A su vez, identificaron como actores de la misma a personas foráneas, no indígenas, procedentes en algunos casos de países vecinos y en otros de distintos departamentos de Colombia, grandes capos del narcotráfico, nacionales y extranjeros, así como terratenientes. También, gobiernos de países vecinos que apoyaron el narcotráfico y la corrupción de las autoridades colombianas cuando eran susceptibles de sobornos (Información suministrada durante el trabajo de campo, abril de 2013).

En cuanto a sus móviles, coincidieron en reconocer que eran intereses de carácter económico, aunque algunos destacaron que también eran intereses de poder, específicamente dominio territorial sobre los pueblos indígenas y en la política local y regional. 
Sobre los métodos o repertorios de esta violencia, señalaron que eran diversos y degradados: explotación mediante el trueque inequitativo e injusto que en otros tiempos, incluso muy lejanos, como la Cauchería, otros colonizadores habían utilizado; invasión y despojo de sus territorios ancestrales; migración forzada a países vecinos o desplazamientos forzados en el mismo país; muerte, terror y tortura para intimidar o coaccionar; y división comunitaria y familiar.

En cuanto a sus efectos, manifestaron que eran diversos y negativos. Coincidieron al señalar dentro de los mismos la afectación sobre sus culturas y su identidad en términos de pérdida de autonomía, aplicación de usos y costumbres y despojo del territorio; ruptura de su unidad comunitaria y familiar; afectación sobre la vida en su consideración más amplia, y la integridad de las comunidades; la generación de prácticas violentas, individualistas y emergencia de sentimientos negativos como la envidia y la ambición; alteración en el proyecto de vida familiar y de los jóvenes; pobreza y miseria.

\section{La violencia del conflicto armado}

Esta violencia ha hecho presencia en sus territorios solo en tiempos recientes y con menor intensidad, comparados con la expresión del mismo en otros escenarios del país. No obstante, sus actores, repertorios e impactos se han hecho sentir con la contundencia necesaria para victimizar a los pueblos en mención.

Sobre la manera cómo llego el conflicto armado a sus territorios precisaron que hasta 1980 solo se registraba allí a la policía, haciendo presencia en dicho año la Infantería de Marina; a comienzos de los noventa arribó la insurgencia, específicamente el movimiento insurgente de las FARC y las autodefensas aparecieron al finalizar la primera década de la presente centuria (Información suministrada durante el trabajo de campo, abril de 2013). En cuanto a sus actores, señalaron a la guerrilla de las FARC, la fuerza pública, concretamente la policía y la Infantería de Marina y las Autodefensas. Con respecto a sus móviles, indicaron que los de la insurgencia y las autodefensas eran de tipo económico asociados al narcotráfico y los de la Infantería de Marina de control de la soberanía del Estado en esta zona de triple frontera. Destacaron que el Trapecio Amazónico ha representado un corredor de tráfico de drogas de uso ilícito.

Se mencionó respecto a la insurgencia que este territorio representó para este actor armado una zona de descanso, aunque también estuvieron vinculados a actividades del narcotráfico. En la actualidad no se registra su presencia, al parecer porque las condiciones propias de la selva Amazónica, 'demasiado extensa y espesa' ${ }^{16}$ y las enfermedades, no favorecieron su consolidación allí y también por el impacto de la política contrainsurgente del gobierno del Presidente Uribe Vélez (Información suministrada

${ }^{16}$ Expresión utilizada por los indígenas al caracterizar las selvas Amazónicas. 
durante el trabajo de campo, abril de 2013). Sobre los métodos y repertorios de esta modalidad de violencia identificaron dentro de los mismos: la vinculación de 'niños y niñas ${ }^{17}$ al conflicto armado, el reclutamiento forzado, el ajuste de cuentas, la amenazas, el desplazamiento forzado, las tomas de localidades, la zozobra y el miedo.

En cuanto a sus impactos o efectos, el mayor de ellos recayó sobre sus culturas, su identidad y su autonomía. Los actores armados desconocieron, negaron e invisibilizaron su condición de pueblos indígenas, sus autoridades y sus procesos comunitarios al intentar imponerles su proyecto armado y sus intereses, tanto los de guerra como los económicos. También generaron un movimiento migratorio a países vecinos, con el desarraigo y todo lo que ello implica, y zozobra y temor en las familias y la comunidades en general.

\section{Las violencias padecidas por los pueblos indígenas de Pebas en la Amazonía Peruana}

En la Amazonía peruana, la reconstrucción de memoria histórica convocó y congregó a 82 representantes de los pueblos indígenas bora, muruy muinane y okaina, de origen colombiano que allí se asientan y de pueblos originarios del Perú, como el yagua. Estos hicieron visibles tres aspectos relevantes: su necesidad apremiante de una elaboración colectiva de memoria histórica de las violencias padecidas; el impacto de la violencia de la cauchería sobre sus vidas y las heridas abiertas que esta modalidad de violencia les ha dejado. Este dolor se hizo visible de muchas maneras: se hizo referencia expresa al mismo. En varias ocasiones se les quebró la voz al hablar de ello, afloraron sus lágrimas o se llevaban su mano al sitio donde se ubica el corazón; decidieron centrar el ejercicio de memoria solo en esta violencia.

\section{La violencia de la cauchería}

Esta modalidad de violencia registra connotaciones especiales para los pueblos indígenas que se asientan en Pebas. Representa uno de los efectos de 'la violencia de la cauchería', registrada en La Chorrera, Amazonía colombiana, en la primera década del siglo XX; y al mismo tiempo, la manera como se expresó en el Perú sobre pueblos indígenas de este país, como el yagua. En esa perspectiva, los pueblos bora, muruy muinane y okaina, asentados en Pebas, son víctimas y sobrevivientes victoriosos de la violencia cauchera registrada en Colombia; y los yagua, víctimas y sobrevivientes de la cauchería peruana. Los tres primeros son herederos de antepasados que vivieron el horror de la cauchería en Colombia y a su vez, el desarraigo producto de su movimiento migratorio forzado al Perú. En cuanto al pueblo yagua, si bien no tuvo que soportar ni registrar la violencia degradada y el genocidio que esta misma actividad generó en la Chorrera, el Encanto

\footnotetext{
${ }^{17}$ Se entiende por niño todo menor de 18 años, asumiendo el criterio internacional de diferenciación.
} 
o la Araracuara en la Amazonía colombiana, sí implicó su explotación, que asumió el rango de esclavización por parte de empresarios del caucho de su país (Información suministrada durante el trabajo de campo, abril de 2013).

Coincidieron todos los pueblos al señalar con respecto a su forma de vida antes que llegara esta violencia a sus territorios, que su recuerdo sobre ese momento histórico resulta muy agradable y gratificante dado que en él se registraron condiciones especiales, acordes con sus culturas, usos y costumbres, armónicas y muy diferentes de la barbarie y el genocidio que sobrevino con la cauchería. En cuanto a los actores de esta violencia, señalaron a Julio Cesar Arana, Miguel Loaiza, Benjamín Larraniaga, Marcos Nicolines Silva, Oliverio Cárdenas y a los barbadenses contratados por la Casa Arana que hacían las veces de capataces; y como países responsables, a Gran Bretaña y Perú (Información suministrada durante el trabajo de campo, abril de 2013).

Con respecto a sus móviles, fueron contundentes al identificar los intereses económicos representados en las ganancias del caucho, pues como alguno de ellos expresó, "era por entonces el recurso natural más costoso del mundo".

Con relación a sus métodos o repertorios, señalaron el asesinato individual y colectivo, las diversas y degradadas torturas, las ejecuciones extrajudiciales y la explotación, esclavización, exclusión, negación y racismo. A su vez identificaron sus impactos, señalando la afectación sobre sus culturas, su identidad y su supervivencia como pueblos; realidad que se hizo evidente en diversas e irreparables pérdidas: vidas de seres queridos, lengua materna, usos y costumbres, desintegración y separación de los pueblos, desintegración y disminución de sus clanes, migración forzada al Perú abandonando su territorio ancestral y sus parientes, desarraigo en el lugar de asentamiento en ese país y la vergüenza de identificarse como indígenas en el presente, entre otras.

\section{Ejes articuladores de las violencias padecidas}

Las violencias padecidas por los pueblos de las Amazonias en mención se registran en distintos tiempos o en tiempos compartidos, en modalidades específicas que las diferencian y son ejecutadas por diversos actores. No obstante, evidencian un eje articulador que subyace a todas y las transversaliza: el racismo y la exclusión que diversos actores han ejercido contra ellos manteniendo en el tiempo los criterios de diferenciación racial adoptados por los españoles colonizadores que arribaron en los siglos XV y XVI a los territorios ancestrales de los pueblos indígenas latinoamericanos (Información suministrada durante el trabajo de campo, abril de 2013).

La raza como categoría mental cuyo origen se ubica en la modernidad, se ha perpetuado como experiencia de dominación moderna / colonial, y de poder capitalista moderno / colonial (Lamus, 2012, pp. 17-18). Debe tenerse en cuenta que la 'raza', más que una realidad biológica es una construcción social en cuyo nombre se han soportado 
diversas modalidades de dominación e incluso, se han perpetrado violencias con inimaginables niveles de degradación e incluso genocidios. Ellas han galopado sobre la equivocada creencia de superioridad racial, cultural y económica frente al indígena, discriminación y exclusión del mismo por considerarlo en el último eslabón de la base social, codicia y deseo de enriquecimiento rápido a costa de los territorios indígenas y sus recursos y modelos económicos hegemónicos excluyentes (Hernández, 2006, p. 180).

\section{Reconocimiento colectivo de su resistencia indígena}

La investigación realizada permitió identificar como resistencia cultural la que ejercen estos pueblos amazónicos (Información suministrada en trabajo de campo, abril y septiembre de 2013). En palabras del pueblo okaina: "La resistencia de la lucha indígena es para no perder nuestras costumbres, cultura y nuestro conocimiento, para que otros no se apoderen de lo nuestro" (Información suministrada en trabajo de campo, septiembre de 2013). Esta resistencia ofrece características propias: se genera, centra y dinamiza en la defensa de las culturas, no admite el uso de la violencia. Sus métodos son esencialmente culturales sin excluir otros de carácter social y se soporta en la espiritualidad, las autoridades espirituales y los conocimientos ancestrales.

Se destaca que en esta modalidad de resistencia indígena, la memoria representa un mecanismo de resistencia y a su vez de fortalecimiento de la misma. La resistencia de los pueblos en mención ofrece diversos logros, siendo quizás el más importante de ellos, su pervivencia a pesar del genocidio cauchero y demás violencias registradas.

\section{La resistencia indígena de los pueblos del Trapecio Amazónico}

Para los pueblos indígenas asentados en el Trapecio Amazónico, la resistencia indígena significa capacidad de lucha sin violencia en defensa de la cultura, la autonomía y el territorio; y mecanismo de unidad y cohesión que hace posible la pervivencia y la armonía (Información suministrada en trabajo de campo, abril y septiembre de 2013). El origen de su resistencia se ubica en el respeto por su espiritualidad, la naturaleza y el conocimiento ancestral, así como también en las enseñanzas de sus ancestros.

La resistencia de nosotros los tikuna viene de nuestra historia ancestral, de los primeros padres tikuna: Yoi, Ipi y Gutapa, que tuvieron el valor de defender las vidas, que son los clanes y culturas. La resistencia que hemos tenido los pueblos de esta selva, es la misma producción que tiene nuestra madre tierra. (Afirmación del pueblo tikuna, trabajo de campo, abril de 2013)

Estos pueblos se reconocen como pacíficos y señalan que su resistencia también es pacífica. En cuanto a sus métodos, todos coincidieron al señalar el carácter no violento de los mismos, identificando dentro de ellos sus organizaciones propias, sus autoridades espirituales, su unidad, su educación y su guardia indígena. 
Estar unidos, en armonía, no olvidar sus tradiciones. Los abuelos siempre nos enseñaron a mantener las costumbres como son: el baile tradicional, los colores naturales como es: el huito. También la cestería, las bebidas, comidas típicas. En ellas encontramos: la mazamorra y la patarasca; las plantas medicinales y la espiritualidad. Sin ello no tuviéramos resistencia. (Afirmación del pueblo tikuna, trabajo de campo, abril de 2013)

Los métodos: talleres de concientización, formación y capacitación de líderes, autonomía y defensa de nuestros territorios y la cultura, conformación de la guardia indígena en cada una de las comunidades, conformación de las organizaciones indígenas: Acitam, Aticolla y Azcaita, conformación de la autoridad propia, conformación de la escuela de formación democrática. (Afirmación de jóvenes tikuna, trabajo de campo, abril de 2013)

Reconocieron también que su ejercicio de resistencia ha registrado diversos y significativos alcances, identificando dentro de estos su organización comunitaria, la protección de sus culturas y territorios, mantener sus autoridades espirituales y la elaboración de sus planes de vida y reglamentos internos, entre otros.

\section{La resistencia de los pueblos indígenas de Pebas en la Amazonía peruana} Para los pueblos indígenas de la Amazonía peruana su resistencia es lucha pacífica contra todas las formas de violencia, directas e indirectas. Dentro de las primeras, los asesinatos, torturas y el genocidio de la cauchería; y dentro de las segundas, todas las modalidades históricas de exclusión, explotación y dominación. También es percibida como forma de lucha política y manera de estar organizados (Información suministrada en trabajo de campo, abril y septiembre de 2013).

Los significados de la lucha o resistencia indígena son: es una lucha pacífica que hacemos nosotros, y si no nos dan respuesta ¿Qué hacemos?, una lucha de la oposición política [...]. (Afirmación del pueblo muruy muinane de Pebas, trabajo de campo, septiembre de 2013)

Desglosemos la palabra y encontremos su significado. En el idioma bora decimos lucha taja, resistencia. Taja es palabra que proviene de vencimiento, conquista, dominación, victoria, triunfo, la cual puede ser lucha física o lucha espiritual; $a b c$, es palabra que proviene de resistir, aguantar, soportar, tolerar. Por ejemplo los bora resistimos el rechazo, la discriminación, el olvido de los gobernantes [...] ¿Cuántos atropellos hemos tenido?, el rechazo por ser indígenas, ser discriminados, cuando nos miraban nosotros no podíamos o podemos, hasta la actualidad misma, expresarnos, dialogar con cualquier persona en su idioma [...] nosotros aún seguimos resistiendo a ese rechazo, a esa discriminación y al olvido de los gobernantes. (Afirmación del pueblo bora de Pebas, trabajo de campo, septiembre de 2013) 
Su resistencia también es cultural y por ende, la intencionalidad de la misma se centra en la protección de sus culturas, su identidad y sus usos y costumbres. A su vez, su origen se ubica en el Dios creador de cada pueblo y las plantas sagradas que les entregó al momento de su origen, y en su arraigo al territorio.

Por la defensa de nuestro territorio entre otros. ¿Por qué?, porque nosotros como pueblos indígenas, nosotros no tenemos de ninguna manera que dejar que otras personas vengan a gobernar dentro de nuestro territorio y muchas cosas más que nos pertenecen, como los peces, los arboles maderables, entonces ese es el origen de la resistencia y la lucha acá dentro de nuestra jurisdicción. (Afirmación del pueblo murui muinane de Pebas, trabajo de campo, septiembre de 2013)

Sus métodos de resistencia han sido diversos y propios: sus organizaciones también, la continuación de sus usos y costumbres, su unidad, su participación comunitaria, sus ritos y sus plantas sagradas, sus fiestas y el diálogo.

Nosotros como pueblos indígenas vamos siempre a estar organizados y frente a una lucha o resistencia vamos a estar todos porque uno solo no puede, entonces todos unidos luchamos y vencemos [...] de igual manera como por ejemplo acá en nuestro sector, nosotros para poder enfrentar una situación, como por ejemplo ahora mucha gente está mirando nuestra riqueza, mucha gente quiere entrar pero uno no lo va a permitir entonces para eso está la legislación, para nosotros como pueblos unidos frente a eso hacer una lucha o una resistencia, por comunidad [...]. (Afirmación del pueblo murui muinane de Pebas, trabajo de campo, septiembre de 2013)

Los métodos de la lucha o resistencia indígena es organizando las fiestas, participando en las instituciones educativas con temas relevantes sobre la cultura, compartiendo con la juventud sobre la reforestación de las plantas medicinales y el uso de las mismas para las diferentes enfermedades, esa es nuestra resistencia, ese es un método que nosotros venimos haciendo en nuestras comunidades bora para que los niños también conozcan todas esas cosas. (Afirmación del pueblo bora de Pebas, trabajo de campo, septiembre de 2013)

Los pueblos en mención manifestaron que su resistencia se ha expresado en su ejercicio de transmisión de la memoria, su ritualidad y sus organizaciones. También que era una resistencia con alcances, dado que ha permitido la conservación perfectible de sus culturas y su identidad y la creación de sus organizaciones locales, regionales y nacionales.

La lucha o resistencia nos sirvió para conservar la originalidad de nuestra cultura valorando la importancia de nuestra identidad y para que los niños y niñas de la generación 
actual no se sientan menos que los demás si no que sigan practicando por siempre las fiestas culturales de nuestro pueblo bora. (Afirmación del pueblo bora de Pebas, trabajo de campo, septiembre de 2013)

[...] entonces la lucha nos ha servido para combatir los diferentes tipos de violencia, para autodeterminarlos [...] esto no se queda acá, hay que hacer una demanda a nivel regional, una demanda a nivel nacional, una demanda internacional [...] eso ya debe culminar para nosotros, la lucha ha ayudado para liberarnos de los diferentes tipos de violencia, para auto-determinarnos y mostrar al mundo entero todos los genocidios [...] (Afirmación del pueblo murui muinane de Pebas, trabajo de campo, septiembre de 2013)

\title{
El poder pacífico transformador de los pueblos de las Amazonias mencionados
}

Los pueblos Amazónicos manifestaron que tienen un poder pacífico transformador y que este ha desplegado su liderazgo al igual que otras capacidades y competencias y les ha permitido hacer tránsito de víctimas a sobrevivientes victoriosos (Información suministrada en trabajo de campo, abril y septiembre de 2013).

\begin{abstract}
Los indígenas bora y okaina tenemos la capacidad de transformar los impactos de la violencia por un impacto de éxito por medio de acuerdos firmes, organizaciones que respeten las formas de los pueblos indígenas haciendo cumplir nuestros derechos que nos amparan como indígenas, es decir mostrar el éxito con hechos reales de los indígenas (Afirmación de los pueblos bora y okaina de Pebas, trabajo de campo, septiembre de 2013)

Si como la inteligencia de los chamanes, funcionando a través de la guía espiritual, también con grandes líderes luchando por el bienestar y desarrollo de nuestros pueblos indígenas, también con estudios que van enfocados en la conservación y el rescate de las memorias ancestrales (Afirmación de jóvenes tikuna, trabajo de campo, abril de 2013)
\end{abstract}

Este poder no es un poder cualquiera: es pacífico y puede transformar la realidad, reposa en cada uno de ellos y en todos, aunque muchas veces se desconoce que se posee. Este poder les ha devuelto la confianza en sí mismos y la esperanza en el futuro, han avanzado perfectiblemente mediante su ejercicio, pero ahora todos coinciden en la necesidad de centrar este poder en el 'canasto o árbol de la abundancia', que se ha convertido en uno de sus más importantes retos (Información suministrada en trabajo de campo, abril y septiembre de 2013).

$\mathrm{Al}$ describir este poder, el pueblo bora asentado en Pebas lo asemejó con un árbol de achiote considerando que era este un árbol sencillo que pasa desapercibido, pero que ofrece diversos y valiosos usos: es fuerte, medicinal y cultural, permite participar en las fiestas y aleja los insectos, entre otros. 
En cuanto al origen de este poder, los pueblos Amazónicos lo ubicaron en el impacto de las violencias que les llevo a desplegar este poder; sus formas propias de organización, su capacidad de diálogo que es ancestral; y en instituciones modernas como la guardia indígena.

El origen del poder pacifico transformador se encuentra en que después de sufrir amenazas, humillaciones, ver muertos, pasar hambre, sed, le da a uno ganas de superar los males que se han vivido. (Afirmación del pueblo tikuna, trabajo de campo, abril de 2013)

Utilizan mucho el dialogo y también hay tiempos en que ellos preparan la chicha, el masato y se reúnen las familias para dialogar, compartir y si hay problemas, y muchas veces piden ayuda de los vecinos (Afirmación del pueblo yagua del Trapecio Amazónico, trabajo de campo, abril de 2013)

Con respecto a los logros de este poder, reconocieron que el principal de ellos había sido su transición de víctimas a sobrevivientes victoriosos, aunque admitieron al respecto que aún faltaba mucho camino por andar en su proceso de recuperación y reparación. Identificaron junto a este logro: organizarse a pesar de la tragedia que representó para estos pueblos la violencia cauchera y los impactos de las otras violencias; mantener perfectiblemente sus culturas, identidad, usos y costumbres; mantener y proteger sus territorios; lograr visibilidad regional, nacional e internacional; contar con instituciones como la guardia indígena, tener profesionales abogados, enfermeros, algunos bilingües y contar con educación primaria, secundaria, superior y bilingüe.

\section{Conclusiones}

- El estudio evidenció la necesidad de abordar la Amazonía de manera integral, reconociendo las fortalezas y amenazas de esta región, pero también los pueblos indígenas que se asientan allí, sus culturas, las violencias que han padecido, su resistencia cultural y su poder pacífico transformador.

- Los pueblos indígenas amazónicos mantienen viva la memoria de las violencias padecidas, especialmente el impacto de la reconocida como 'la caucheria' y el impacto de las mismas, como heridas sin cicatrizar que se han transmitido de generación en generación.

- La reparación de los pueblos en mención, para cerrar y sanar las heridas causadas por las violencias referidas, tiene mucho que ver con posibilitar, como en este estudio, la reconstrucción colectiva de la memoria de las violencias padecidas; pero también con el reconocimiento de las mismas y la indemnización por parte de los países implicados, que se ha convertido en lo que estos pueblos expresan como 'canasto de la abundancia', brindándoles oportunidades para satisfacer sus necesidades vitales ${ }^{18}$,

${ }^{18}$ Como la protección de la vida, el territorio, las culturas, la autonomía, acceder a la educación y fortalecer sus procesos comunitarios, entre otras. 
desarrollar sus capacidades y potencialidades, proteger sus culturas y fortalecer sus procesos comunitarios. En igual forma, reconocer su resistencia y su poder pacífico transformador que les ha permitido hacer esa importante transición de víctimas a ‘sobrevivientes victoriosos' y reconocer e integrar en la historia nacional a estos pueblos, sus culturas y su historia, entre otras.

- En forma propositiva, los pueblos indígenas Amazónicos identificaron alternativas para superar las heridas dejadas por las violencias, enfatizando dentro de ellas el fortalecimiento de sus procesos y organizaciones comunitarias, mantener la unidad, el acceso a la educación, mantener la memoria histórica y la reparación integral por los daños causados por las violencias.

- Se destaca que estos pueblos se reconozcan como pacíficos y que admitan que cuentan con un poder pacífico transformador que les ha permitido alcanzar importantes logros, siendo el más importante de ellos: sobrevivir a las violencias que han padecido, especialmente al genocidio de la cauchería, organizarse, proteger sus culturas y territorios, ejercer autonomía y proyectarse un futuro con bienestar y abundancia.

- La resistencia que ejercen estos pueblos ofrece una nueva modalidad: la cultural. Desde esta perspectiva, aporta valiosos elementos teóricos y prácticos que amplían la comprensión de este concepto académico.

- El estudio destaca la articulación de la memoria histórica de las violencias con la construcción de la paz. De una parte, la atención integral de las víctimas representa uno de los ejes del ámbito de acción de la construcción de la paz, pero también en el proceso de reparación es necesario abordar a las víctimas de manera más integral y propositiva, reconociendo no solo su condición de víctimas, sino también su poder pacífico transformador y sus empoderamientos pacifistas.

- La reconstrucción de la memoria histórica de las violencias padecidas por estos pueblos vuelve a hacer visible la violencia cultural en su modalidad de racismo, que se convierte en eje articulador de todas ellas, independientemente del tiempo en que hayan ocurrido y de los actores que las hayan perpetrado. También permite enfatizar en la urgente necesidad de superarlo avanzando en el reconocimiento de la multiculturalidad que es propia a casi todas las naciones del mundo y a su vez, generando y adoptando una interculturalidad que reconociendo las diferencias, permita construir a partir de las mismas formas de relación armónicas y propositivas, profundizando las democracias para poder alcanzar el paradigma que, sin desconocer la riqueza de la diferencia que entrañan los pueblos, permita afirmar que 'la raza humana es una sola' ${ }^{19}$.

${ }^{19}$ Expresión tomada de Lamus, D., (2012) 


\section{Referencias}

ACITAM (2008). Plan de vida de la Asociación de Cabildos Indígenas del Trapecio Amazónico, Programa Amazónico. Amazonas: CODEBA, Editorial Alta Voz Comunicaciones.

Castañeda Salamanca, F. (2002). El indio: entre el bárbaro y el cristiano. Ensayos sobre la filosofía de la conquista de Las Casas, Sepúlveda y Acosta, Bogotá: Alfaomega Grupo Editor S.A.

Centro Amazónico de Antropología y Aplicación Práctica (CAAAP) y Grupo Internacional de Trabajo sobre Asuntos IndígenAs (IWGIA) (2012). El libro azul británico. Informes de Roger Casement y otras cartas sobre las atrocidades en el Putumayo. Perú: Editorial IWGIA- CAAAP.

Chaparro, R. (1998). Territorios Indígenas. Santa Fe de Bogotá: Quebecor Impreandes.

Chaumeil, J.P., Espinosa de Rivero O. y Cornejo Chaparro, M. (Eds.) (2011). Por donde hay soplo. Lima, Perú: Imprenta Asociación Gráfica Educativa.

Comins, I., y Muñoz, F. (Eds.) (2013). Filosofías y praxis de la paz. Barcelona: Icaria.

Donadio, A. (2002). La guerra con Perú. Medellín: Hombre Nuevo Editores.

Galtung, J. (1995). Investigaciones teóricas, Sociedad y Cultura Contemporáneas. Madrid: Editorial Tecnos S.A.

Girard, R. (1958). Indios selváticos de la Amazonía peruana. México: Libro Mex Editores.

Goés, E. (2011). El nacimiento del presente etnográfico: la emergencia del patrón de distribución de sociedades indígenas y familias lingüísticas en las tierras bajas sudamericanas, durante el primer milenio d.c. En Chaumeil, J.P., Espinosa de Rivero, O. y Cornejo Chaparro, M. (Eds.) Por donde hay soplo. Lima, Perú: Imprenta Asociación Gráfica Educativa.

González, J. (1996). Historia de la Amazonía. Santa Fe de Bogotá: Quebecor Impreandes.

Hernández, E. (2000). Cuadernillo pedagógico superación de la impunidad, reparación reconstrucción y reconciliación. Bogotá: Editorial Codice Ltda.

Hernández, E. (2004). Resistencia civil artesana de paz. Experiencias indígenas, afrodescendientes y campesinas. Bogotá: Editorial Pontificia Universidad Javeriana.

Hernández, E. (2006). La resistencia civil de los indígenas del Cauca. Revista Reflexión Papel Político, 11 (1).

Hernández, E. (2009). Resistencias para la paz en Colombia: significados, expresiones y alcances. Reflexión Política, (21). 
Hernández, E. (2012). Intervenir antes que anochezca. Mediaciones, intermediaciones y diplomacias noviolentas de base social en el conflicto armado colombiano. Bucaramanga: Litografía La Bastilla.

Hernández, E. y Salazar, M. (1999). Con la esperanza intacta. Experiencias comunitarias de resistencia civil no-violenta. Bogotá: Editorial Arte y Folito.

Hildebrand, M. y Brackelaire, V. (2012). Guardianes de la Selva. Gobernabilidad y autonomía en la Amazonía colombiana. Bogotá: Digiprint Impresión.

Lamus, D. (2012). El color negro de la (Sin) razón blanca: el lugar de las mujeres afrodescendientes en los procesos organizativos en Colombia. Bucaramanga: Publicaciones Universidad Autónoma de Bucaramanga.

Muñoz, F. A. (Ed). (2001). La paz imperfecta. Granada: Editorial Universidad de Granada.

Muñoz, F. A. y Bolaños, J. (Eds.). (2011). Los habitus de la paz. Teorías y prácticas de la paz imperfecta. Granada: Editorial Universidad de Granada.

Muñoz, F., A., Jimenez, J. M., (2012). La paz partera de la historia. Granada: Editorial Universidad de Granada.

Muñoz, F., Herrera, J., Molina, B., y Sánchez, S. (2005). Investigación de la paz y los derechos humanos desde Andalucía. Granada: Editorial Universidad de Granada.

Navia, G. (1995). Conozcamos la selva Amazónica. Leticia: Fondo Editorial Masayaki.

Pineda, R. (2011). Antropólogos y movimientos indígenas en la Amazonía oriental colombiana: una visión panorámica (1960 - 2000). En Chaumeil, J., Espinosa de Rivero, O. y Cornejo Chaparro, M. (Eds.). Por donde hay soplo. Lima, Perú: Imprenta Asociación Gráfica Educativa.

Salazar, (1992). La investigación - acción participativa. Inicios y desarrollos. Santafé de Bogotá D.C.: Editora Géminis Ltda.

Sánchez, G. (2006). Guerra, memoria e historia. Medellín: Editorial Lealon.

Sting y Dutilleux, J. P. (1989). Amazonía. La lucha por la vida. España. Madrid: Ediciones Jean-Claude Lattés.

Várese, S. (2011). Amazonía: ¿̇cuarenta años de diálogo antropológico o de monólogo ideológico. En Chaumeil, J.P., Espinosa de Rivero, O. y Cornejo Chaparro, M. (Eds.). Por donde hay soplo. Lima, Perú: Imprenta Asociación Gráfica Educativa. 
